\title{
The role of siblings in the process of forming life satisfaction among young adults - moderating function of gender
}

\author{
Paulina Szymańska ${ }^{1}$ (D) \\ Published online: 7 May 2020 \\ (C) The Author(s) 2020
}

\begin{abstract}
The main aim of the study was to explore the relationship between life satisfaction and sibling bond quality, with gender playing a moderating role. The sample consisted of 276 young adults with a single biological sibling. The participants completed three questionnaires: a sociodemographic survey, the STQ-Now (quality of the sibling relationship) and the SWLS (level of life satisfaction). No difference was observed between men and women regarding life satisfaction; however, the gender constellation in a sibling dyad was found to be statistically significant. Same-sex pairs scored higher on life satisfaction than cross-sex siblings. A positive relationship with a brother or a sister based on mutuality correlated with high overall satisfaction with life, while criticism, competition and apathy were associated with lower general satisfaction. Additionally, two of these relations (i.e. mutuality and apathy) were moderated by gender. Lastly, representatives of the Supportive type of relationships obtained higher levels of life satisfaction than the Ambivalent or the Reluctant types. The findings suggest that siblings play an essential role in shaping psychological well-being. As early adulthood is a stage characterised by multitasking and various challenges, the formation of positive, adaptive and supportive sibling bond may maintain good life satisfaction. The findings also underline the significance of gender combination in the relationship.
\end{abstract}

Keywords Sibling relationship $\cdot$ Early adulthood $\cdot$ Life satisfaction $\cdot$ Brothers $\cdot$ Sisters

\section{Introduction}

Early adulthood is a period of life when achieving high life quality depends strongly on the successful realisation of a range of psychosocial developmental tasks, including gaining autonomy, building emotional and social skills though finding a reference group and starting a family; it is also a time of establishing an identity, mostly by discovering one's own interests, preferences and constituting opinions (Havighurst 1981). Accumulating evidence has proven that married people are characterised by higher levels of life satisfaction and better mental health than those who are not (Uecker 2012; Zhu et al.

Electronic supplementary material The online version of this article (https://doi.org/10.1007/s12144-020-00776-3) contains supplementary material, which is available to authorized users.

Paulina Szymańska

paulina.szymanska@uni.lodz.pl

1 Institute of Psychology, University of Lodz, ul. Smugowa 10/12, 91-433 Łódź, Poland
2018). Involvement in an intimate relationship enhances the level of support and helps to meet the needs for human affiliation and love. Such well-being also differs between genders (Öz Soysal 2016; Tay et al. 2014; Di Tella et al. 2003) and may be heightened by social participation, fulfilling civic obligations and beginning professional activity (Cicognani et al. 2008; Haase et al. 2012). However, changes in social requirements and modifications in the values hierarchy have resulted in a tendency to postpone the moment of engaging in adult activities and responsibilities (Goldscheider and Goldscheider 1999). The mean age of marriage and leaving home has increased, as has the moment of finding a first job and gaining independence (Stańczak et al. 2016). Extensive social transformations have a strong influence on individual growth, thus complicating the accomplishment of such tasks independently. Therefore, with regard to the therapeutic and developmental context, it is of growing importance to shape adaptive bonds with the closest people and finding additional support sources during this life stage. Considering the abovementioned issues, the paper examines the relationship between sibling bond quality and satisfaction with life during early adulthood. 


\section{Life Satisfaction among Adults}

The literature contains a number of definitions of well-being, quality of life and life satisfaction. The most commonly-used approach treats well-being as a subjective set of opinions and appraisals of one's own life, while life quality is regarded as being a more objective measure focused on the external factors and circumstances impacting daily activities. Well-being consists of various psychological constructs, processes and phenomena, such as positive and negative emotional reactions to life events or cognitive judgments on life and its domains (Arthaud-Day et al. 2005; Diener 2006; Diener et al. 1999). This approach conceptualizes satisfaction with life as an individual evaluation of one's own life in general and, despite some correlation, tends to be rather independent of the affective aspects of well-being or objective quality of life (Lucas et al. 1996; Pavot and Diener 2008).

Top-down, dispositional models assume that life satisfaction is formed by chronically accessible information emanating from personality traits, such as neuroticism or extraversion, as well as from satisfaction with various life domains, e.g. work or marriage, and is partially dependent on genetic factors. A slightly different approach is presented by bottomup models, which assume life satisfaction has situational roots, and that it exerts an influence on satisfaction with each life domain (Stubbe et al. 2005). Adding to that affective responses influencing individual experiences or adaptation strategies, the relationship between life and domain satisfaction appears unclear and needs further verification (Heller et al. 2004)

Life satisfaction affects psychosocial functioning: a high level is associated with better job performance and higher income (Graham et al. 2004; Lucas et al. 2004), as well as greater satisfaction with marriages or other romantic bonds. Cross-sectional studies have also confirmed a relationship between life satisfaction and the size of one's friendship group, the degree of social support and companionship with coworkers (Pinquart and Sörensen 2000; Staw et al. 1994). Life satisfaction also seems to be an important component of mental and physical health: happy, satisfied people manifest fewer psychopathological symptoms, such as depression, phobia or anxiety (Diener and Seligman 2002; Lyubomirsky et al. 2005) and are less prone to substance abuse (Bogner et al. 2001). They tend to feel more energetic, healthier and report lower pain intensity (Gil et al. 2004; Mroczek and Spiro 2005).

Knowing the importance of life satisfaction for human daily functioning, it is crucial to foster and maintain its high level in adulthood, especially the early phase. Studies show that young adults are at special risk of mental disorder (Szafraniec 2011) and need additional support to ease their passage into a new life period. Unfortunately, it appears that they are increasingly subject to discomfort, anxiety and other mental problems during this period: Stallman (2010) reports that more than $80 \%$ of students declared elevated levels of distress, nearly one-fifth reported symptoms of serious mental illness, and almost two-thirds reported mild or moderate issues. However, shaping high life satisfaction may improve the psychological and social functioning of young adults and ameliorate various health disorders.

\section{Siblings Role in a Developmental Process}

Both brothers and sisters play a major role in a human development, and it has been estimated that $83 \%$ of children perceive their siblings as one of the most significant and valuable people in life (Kosonen 1996). From the first moments of life, siblings are constant companions in both positive and negative life events, often becoming a role model. Spending time and playing with siblings, as well as learning together and experiencing difficult situations, help improve social competence and self-control; in addition, observation of the sibling reactions also strengthen emotional skills, such as empathy (Brody and Kim 2003; Cyron et al. 2017; Jenkins Tucker et al. 2013). The relation with a brother or a sister in childhood and adolescence is diverse and may have also negative aspects. For instance, the necessity to share common space and goods and fight for attention from parents may generate conflict and aggression (Caspi 2011; Kolak and Volling 2011). Parenting style can also play a significant role; unequal treatment can trigger competitive or even delinquent behaviours between children depending on their genders or favoured status, i.e. being favoured or disfavoured (Scholte et al. 2007). Social learning theories propose that one sibling, typically the older one, tends to serve as a role model; younger children sometimes appear to imitate both the adaptive and nonadaptive behaviours of the older sibling, such as violence or drug use. For example, Kothari et al. (2014) reported a positive correlation between adult men and teenage siblings in the consumption of beer and high-percentage alcohol, and use of tobacco.

The relation with sibling does not remain stable throughout life, but is subject to changes related to passing through subsequent stages of development (Goetting 1986). While it may be strong during childhood and adolescence, but often also ambivalent, the bond can be weakened in adulthood as a result of dealing with such developmental tasks as leaving home or starting a family (White 2001). Doherty and Feeney (2004) indicated that singles tended to display a stronger attachment to their siblings then their dating partners. Neither siblings, mother, father nor friend were the main attachment figure in adulthood, but rather the life partner; however, partners and family members, including brothers and sisters, provided the basis for a sense of security, whereas friends were perceived rather as a source of reassurance. However, the relationship with a sibling is still perceived as close and meaningful, even 
if the frequency of communication had decreased (Hamwey et al. 2019).

During adulthood, siblings represent a fundamental source of emotional and instrumental support. A study by White and Riedmann (1992) found two-thirds of participants treated a sibling as a friend and one-third reported calling them for help or advice if needed. The form of support is dependent on gender; women tend to be more emotionally supportive, and men more practically so. Sibling support gains importance when facing difficulties such as widowhood or coming out (Haxhe et al. 2018; Merz \& De Jong Gierveld 2016). It has been proven that experiencing stressful life events can strengthen the bond (Cicirelli 1995; Goetting 1986); however, maintaining a close relationship during adulthood, and hence this support, may require positive, regular contact (Voorpostel \& Blieszner 2008).

A valuable insight into sibling function at various stages of life has been provided by sibling typologies. Murphy distinguishes three types of siblings in childhood based on interviews with the parents of preschool children (1992, as cited in Stewart et al. 1998): the first is the Caretaker, who often takes parental and caring activities, the second is the Buddy, behaving as a friend and partner in common play and the third is the Casual, seeming to be disengaged in the everyday functioning of their sibling. Regarding the developmental changes that take place across the lifespan, Stewart et al. (2001) developed an adult sibling typology that consisted of five, diverse types: Supportive, Longing, Competitive, Apathetic and Hostile. Similar profiles were drawn up by Walęcka-Matyja (2018) and for the elderly by Gold (1990). These findings indicate some stability of the relationships during adulthood, but also point that both warm and distant or conflictual relationships can exist between sisters and brothers at that time.

\section{Siblings Relationship Quality and Life Satisfaction}

Even though the relationship with a sibling changes during the transformation to adulthood, it seems that it nevertheless retains its impact on the basic domains of life (Hindle and Sherwin-White 2014). Increased levels of stress, the lack of stability and the need to deal with a variety of challenges during early adulthood result in lower life satisfaction and the deterioration of mental health (Stallman 2010) as well as various psychosocial and biological consequences, such as autonomy issues (Seiffe-Krenke 2006) or transformations within family systems (Fujita and Diener 2005; SeiffgeKrenke 2013; Whiteman et al. 2011). Although brothers and sisters appear to be "a protective factor" in dynamicallychanging surroundings, offering support and giving an opportunity for undisturbed psychosocial growth, few studies have examined the relationship between the quality of the sibling bond and overall life satisfaction. Most conducted studies treat the sibling relationship as bidimensional, i.e. positive-conflictual, suggesting that a harmonious and stable relationship with a brother or a sister is positively connected with psychological well-being (Milevsky 2018a; Sherman et al. 2006). Partial evidence suggests that acceptance and respect toward a sibling may be associated with a lower level of depressive symptoms, as well as less anxiety and different somatic problems (Walecka-Matyja 2018). Additionally, the quality of the bond appears to influence the general perception of health and satisfaction with couple relationships (Palmer 2017). However, most importantly, previous research has referred mostly to various aspects of well-being than to life satisfaction itself: only a few studies on sibling support indicate that a high level of support predicts an increased level of life satisfaction (Hollifield and Conger 2015; Milevsky 2005).

Researchers have attempted to understand the relationship between psychosocial well-being and the type of relationship with siblings, but none of the previous studies has evaluated adult sibling types in terms of general life satisfaction. The present research complements existing knowledge with previously unstudied aspects, by precisely describing the link between the quality of the sibling relationship, including sibling types, and satisfaction with life. As demographic variables are known to play a significant role in the nature of the sibling relationship, (Öz Soysal 2016; Tay et al. 2014) the present study also considers the moderating role played by gender.

\section{The Present Study}

In sum, although there is partial evidence combining the functioning of siblings with the well-being among young adults, some issues remain to be uncovered. Firstly, despite the fact that the role of sociodemographic factors regarding the quality of sibling bonds seems to be clear (Jensen et al. 2019; Öz Soysal 2016; Tay et al. 2014; Di Tella et al. 2003), its impact on the process of shaping the relation between the sibling bond and life satisfaction needs to be further clarified. Secondly, some studies suggest that the close sibling bond has a positive impact on satisfaction; however, further detail is needed regarding the role played by sibling type, especially during early adulthood (Milevsky 2018b; Milevsky et al. 2005; Walęcka-Matyja 2018). Hence, the following hypotheses were formed:

H1. Women are more satisfied with life than men.

H2. Young adults from the same-sex sibling pairs are more satisfied with life than those from cross-sex pairs.

H3. Siblings that are in more frequent contact with each other are more satisfied with life.

H4. A positive relationship with a sibling is connected with a higher level of life satisfaction, and a negative one with lower satisfaction. 
H5. The relation between the quality of the sibling bond and satisfaction with life is moderated by gender constellation in a sibling pair.

H6. The type of sibling relationship differentiates the level of life satisfaction.

\section{Method}

\section{Procedure and Data Collection}

All research procedures were performed in accordance with international ethical standards (e.g. 1964 Helsinki declaration and its later amendments) and National Science Centre recommendations for studies involving humans. The participants were selected using purposive sampling, by the snowball technique. Although purposive sampling is a non-representative method it allows the targeting of a specific group, one that is homogeneous regarding chosen characteristics and heterogeneous regarding others, thus enabling that level of variation in the sample to be maximised. It was assumed that all participants should originate from full families and had only one biological sibling in the same age range, i.e. early adulthood. The sample was diverse in terms of education level, field of study, place of residence, marital status, as well as sibling age and sibling gender.

The study was conducted using a paper-pencil method, both in groups and individually, in the presence of a researcher or a trained cooperating person. The participants were informed that the study was anonymous, and that its results will be used only for scientific purposes. Participation in the survey was voluntary. Oral consent was obtained from each person. As access to both participant and their siblings is significantly limited because of the increased mobility of young adults and the irregular contact between siblings during this life stage, the study did not include sibling pairs, but individual respondents meeting the mentioned criteria. To avoid high level of bias and low level of reliability theoretical framework, participant inclusion criteria and tool selection were wellconceived based on a variety of literature and consulted with two specialists in developmental psychology.

\section{Participants}

The sample consisted of 276 young adults ( 189 women and 87 men) aged between 18 to 35 years old $(\mathrm{M}=23.81, \mathrm{SD}=3.87)$; of these, 133 had sisters and 143 brothers. Participants were recruited from rural and urban areas in one voivodship in the centre of XXX (country name blinded). The mean age of the sibling (M) was 25.32 years, with a standard deviation (SD) of 4.64. In addition, 183 were students and they represented 45 different fields of study. Regarding marital status, $50 \%$ were single, $39 \%$ remained in an informal relationship and $11 \%$ were married.

\section{Measures}

The following questionnaires were used to verify the hypotheses: the Satisfaction with Life Scale (SWLS), the STQ-Now and an expanded form designed by the author that included not only basic sociodemographic data such as gender, age, education and place of residence, but also additional questions about the relationship with the sibling.

The Satisfaction with Life Scale (SWLS) (Diener et al. 1985 ) is a short, widely-used questionnaire that allows assessment of overall life satisfaction, interpreted as a cognitivejudgemental process. A number of translated or adapted versions of the SWLS have been used e.g. in Brazil (Gouveia et al. 2009), China (Xiong and Xu 2009), France (Bacro et al. 2020), Germany (Hinz et al. 2018), Latvia (Maslovska et al. 2005) and Mexico (López-Ortega et al. 2016).

The Polish version used in the present study was adapted by Juczyński (2009). Similar to the original tool, it consists of five items referring to the subjective sense of life satisfaction, e.g. "In most ways my life is close to my ideal" or "If I could live my life over, I would change almost nothing". The participant indicates his or her level of agreement with each statement on a scale from 1 (strongly disagree) to 7 (strongly agree). Due to the simple structure and theoretical framework, basing on the assumption that life satisfaction is dependent on the subjective judgment of the individual, the SWLS has been used in research involving both healthy and ill participants (Dorahy et al. 2000; Kováts et al. 2017; Paupério et al. 2012; Shirkavand et al. 2018; Simpson et al. 1996).

The Polish version of the scale has satisfactory psychometric parameters. The test-retest correlations within a six-week period indicated a high level of reliability $(r=0.86)$, and the tool demonstrated good internal consistency based on Cronbach's alpha $(\alpha=0.81)$. Cronbach's alpha was also high for the sample in the present study $(\alpha=0.86)$. Theoretical validity was estimated by analysing relationships with variables that may be connected with satisfaction with life, obtaining statistically significant positive relationships with self-esteem and negative ones with the level of perceived stress and suppressing emotions such as anger or those related to anxiety and depression (Juczyński 2009).

The STQ-Now (Stewart et al. 1998, 2001) is used to evaluate the quality of sibling relationships during adulthood. The original version of the tool comprises 50 items within five subscales (mutuality, criticism, apathy, competition and longing). The Polish adaptation required a few changes. Due to the low level of factor loadings, two items were excluded and a longing subscale was removed based on the results of the EFA. Criticism items from the original version were divided 
between two scales in the Polish adaptation: a criticism and a newly created predominance subscale (Szymańska 2016).

The final adapted tool consists of 48 items grouped into five subscales:

- Mutuality (describing close emotional bond with a brother or sister), e.g. "My brother/sister often tells me that he/she loves me", "I provide my brother/sister with emotional support";

- criticism (illustrating critical, negative attitude towards sibling), e.g. "The younger sibling irritates the older sibling", "My sibling and I tend to argue a lot";

- predominance (assessing the level of superiority and control), e.g. "The older sibling is bossy with the younger sibling", "The younger sibling is always trying to tell the older sibling what he/she should do"

- apathy (referring to the level of indifference towards a brother/a sister), e.g. "The younger sibling does not find the older sibling to be very interesting", "My brother/sister and I hardly ever see each other anymore"

- competition (including items about rivalry between sibling), e.g. "The older sibling tries to out-perform the younger sibling", "My brother/sister seems to always be trying to be better than me".

Participants assess the level of agreement with each statement on a $1-5$ scale (1 - hardly at all; 5 - extremely much).

An analysis of the psychometric properties of the tool revealed that concurrent and discriminant validity was fully satisfactory based on the r-Pearson correlations, for instance high mutuality was related to high social support from siblings, high similarity, intimacy, affection, acceptance; high criticism was negatively linked with emotional support, admiration, intimacy and positively with quarrel or opposition; apathy was negatively connected to general warmth, including similarity or affection, as well as with informational, instrumental, evaluative and emotional support. Cronbach's alpha coefficients, indicating the level of reliability level for the Polish version, were obtained for the following particular scales: mutuality $\alpha=0.94$, criticism $\alpha=0.81$, predominance, $\alpha=0.72$, apathy $\alpha=0.84$, competition $\alpha=0.86$; for the study sample: mutuality $\alpha=0.95$, criticism $\alpha=0.83$, predominance $\alpha=$ 0.72 , apathy $=0.86$, competition $=0.87$.

\section{Data Analysis}

Data was analysed using IBM SPSS Statistics 25. According to the Shapiro-Wilk test, all variables except mutuality were not normally distributed (Table 1); therefore, it was decided to use non-parametric tests, such as the Kruskal-Wallis, MannWhitney U-test and Spearman's Rank correlation. The SPSS extension PROCESS Macro by Andrew Hayes was used to perform moderation analysis. K-Means clustering was applied
Table 1 Results of the Shapiro-Wilk normality test

\begin{tabular}{llll}
\hline Variable & W-Statistic & df & $p$ \\
\hline Mutuality & 0.991 & 276 & 0.098 \\
Criticism & 0.956 & 276 & 0.001 \\
Predominance & 0.966 & 276 & 0.001 \\
Apathy & 0.973 & 276 & 0.001 \\
Competition & 0.928 & 276 & 0.001 \\
Satisfaction with life & 0.985 & 276 & 0.005 \\
\hline
\end{tabular}

$d f$ degrees of freedom; $p$ two-sided statistical significance

to portion the sample into three representative types of sibling relations.

\section{Results}

Results are shown below in order of tested hypotheses.

\section{Life Satisfaction of Young Adults and their Gender}

Firstly, the Mann-Whitney U-test was applied to verify whether a gender differentiates the level of life satisfaction among participants. The null hypothesis that men and women demonstrate similar scores was not rejected $(\mathrm{U}=7878.00, \mathrm{SE}=$ $614.83, p=0.576$ ), indicating that it is unlikely that satisfaction with life during young adulthood differs according to sex (Fig. 1).

Analysis of the data confirmed differences in the life satisfaction level between subsamples representing various gender constellations within a sibling pair $(\mathrm{H}=8.738, d f=3, p=$ 0.033). Pairwise comparison indicates a higher average rank for same-sex siblings than for cross-sex pairs (Fig. 2). Female participants with sisters were more satisfied than male participants with sisters $(H=35.045, \mathrm{SE}=14.767, p=0.018)$ and female participants with brothers $(\mathrm{H}=26.673, \mathrm{SE}=11.601$,

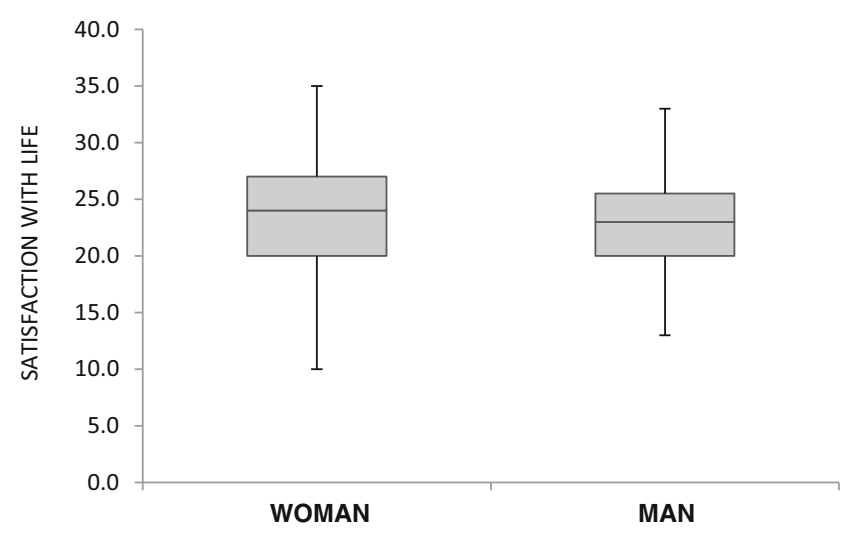

Fig. 1 Rank distribution of life satisfaction across woman and man. Minimum and maximum ranks are presented 
Fig. 2 Rank distribution of life satisfaction across groups representing different gender constellation within participantsibling pairs. Minimum and maximum ranks are presented

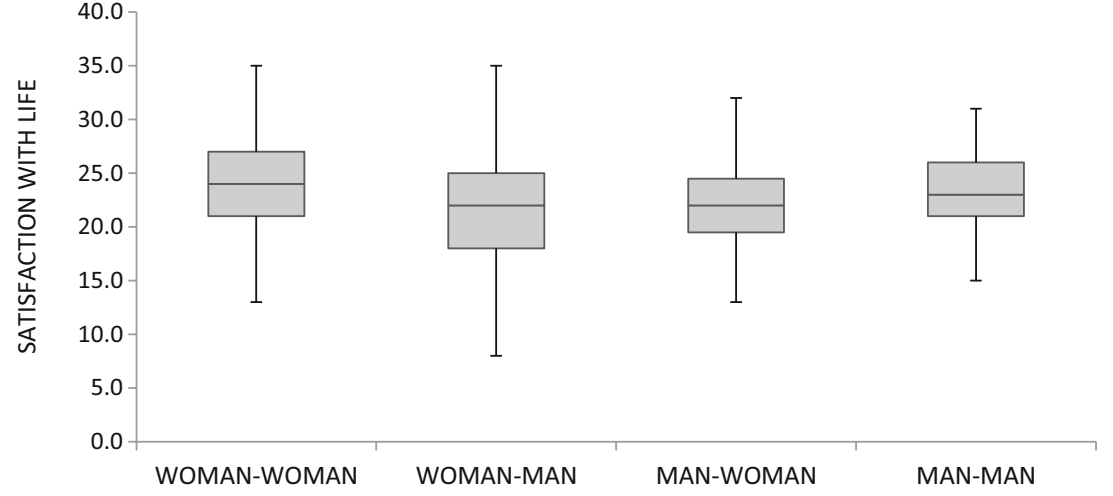

$p=0.021)$. Additionally, there was a slight trend when comparing male participants with sisters to those with brothers $(\mathrm{H}=-30.267, \mathrm{SE}=17.081, p=0.076)$.

\section{Siblings Relationship and Life Satisfaction}

The participants were asked to assess the frequency of contact with sibling as daily, 2-3 times a week, once a week, once a month or rarer. The findings did not confirm the tested hypothesis. No significant differences were found between the four subsamples with regard to life satisfaction $(\mathrm{H}=4.827$, $d f=3, p=0.178)$.

The quality of the relationship between siblings was measured by five variables in the STQ-Now. The positive aspect of the bond and its closeness was assessed using the mutuality subscale, the negative aspect by the criticism, predominance and competition subscales, and lack of interest and indifference by the apathy subscale. The results are shown in Table 2.

The results indicate confirming the hypothesis regarding the relationship between sibling bond quality and satisfaction with life. Participants with a close and intimate relation with a brother or sister tend to be more satisfied with their lives ( $\rho=$ $0.201, p=0.001)$, whereas those more competitive and

Table 2 Correlation between the quality of sibling relationship and life satisfaction

\begin{tabular}{lll}
\hline Variable & \multicolumn{2}{l}{ Satisfaction with life } \\
\cline { 2 - 3 } & $\rho$ & $p$ \\
\hline Mutuality & $0.201^{* *}$ & 0.001 \\
Criticism & $-0.170^{* *}$ & 0.005 \\
Predominance & -0.083 & 0.171 \\
Apathy & $-0.203^{* *}$ & 0.001 \\
Competition & $-0.128^{*}$ & 0.033 \\
\hline
\end{tabular}

$\rho$ Spearman's Rank correlation coefficient; $p$ two-sided statistical significance

*correlation is significant at the level of 0.05 ;

**correlation is significant at the level of 0.01 jealous $(\rho=-0.128, p=0.033)$, or critical and hostile $(\rho=$ $-0.170, p=0.005)$, are characterized as less satisfied. Both high apathy and low involvement in the relationship with sibling $(\rho=-0.203, p=0.001)$ were likewise associated with a low level of life satisfaction.

To verify the hypothesis about the role of gender constellation in the relationship between sibling bond quality and satisfaction with life, moderation analysis was conducted. The results partially supported assumptions (see Supplementary Table in Appendix).

The overall model for mutuality and life satisfaction was significant: $R^{2}=0.116, F(7,268)=5.020, p=0.001$. Gender configuration was found to have a moderating effect (Supplementary Table). Interaction accounted for 3.5\% variance in satisfaction with life $\left(\Delta R^{2}=0.035, F(3,268)=3.499\right.$, $p=0.016$ ). For both types of same-sex sibling pairs, womenwomen $(b=0.003, t(268)=0.056, p=0.956)$ and men-men $(b=0.104, \mathrm{t}(268)=1.275, p=0.203)$, the level of mutuality in the relationship did not predict life satisfaction. For crosssex pairs, i.e. woman-man and man-woman, high mutuality was connected with high life satisfaction $(b=0.256, t(268)=$ 4.033, $p=0.001$ and $\mathrm{b}=0.268, t(268)=2.935, p=0.004$, respectively). The moderation effect is presented in Fig. 3.

Analysis of three hierarchical regression models including separate variables representing the negative aspects of the sibling relationship did not indicate that sibling gender configuration had any moderation effect. The overall model for criticism predicting life satisfaction was statistically significant $\left(R^{2}=0.088, F(7,268)=29.440, p=0.001\right)$. Irrespective of gender constellation, the relationship between independent and dependent variable was similar in all subsamples $\left(\Delta R^{2}=0.016, F(3,268)=1.604, p=0.189\right)$. The regression models were not significant for neither predominance nor competition $\left(R^{2}=0.047, F(7,268)=1.895, p=0.070\right.$ and $R^{2}=0.049, F(7,268)=1.959, p=0.061$, respectively $)$.

The regression model for apathy and life satisfaction explained $11 \%$ of the total variance of life satisfaction $\left(R^{2}=\right.$ $0.107, F(7,268)=4.609, p=0.001)$. Sibling gender configuration was found to demonstrate a moderation effect while controlling for the main effects $\left(\Delta R^{2}=0.036, F(3,268)=\right.$ 
Fig. 3 The moderating effect of gender constellation in a sibling pair on the relationship between mutuality and life satisfaction

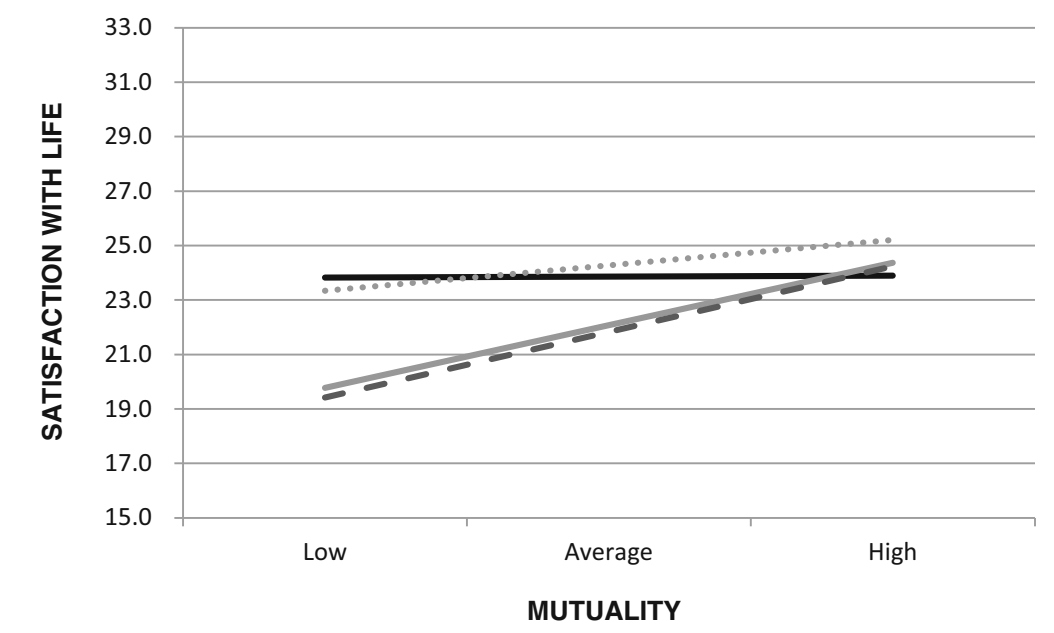

WOMEN-WOMEN
$3.556, p=0.015$, see also Supplementary Table). Examination of the moderation plot (Fig. 4) indicated that in contrast to cross-sex siblings, the relation between apathy and life satisfaction among woman-women siblings $(b=0.020, t(268)=$ $0.297, p=0.767)$ as well as brother-brother pairs $(b=$ $-0.096, t(268)=-1.086, p=0.279)$ was not statistically significant. High apathy determined a low level of satisfaction with life among female participants with brothers $(b=-0.277$, $t(268)=-4.287, p=0.001)$ and male participants with sisters $(b=-0.163, t(268)=-2.018, p=0.045)$.

To verify whether the type of sibling relationship differentiates the level of life satisfaction, cluster analysis was performed. In accordance with previous research (Stewart et al. 1998; Szymańska 2019), the sample was divided into three groups based on the level of the variable measuring the quality of the sibling relationship. The Supportive type $(n=116)$ was represented by participants demonstrating the warmest and most intimate relationship with a brother or a sister, connected with a high level of mutuality. The Reluctant type $(n=79)$ was characterised by a low level of mutuality and a high level of the variables measuring the negative aspects of the bond. Finally, the Ambivalent type $(n=81)$ was characterised by an average level of apathy and mutuality, and by high criticism, predominance and competition.

These subsamples differed in terms of mean life satisfaction $(\mathrm{H}=13.980, \mathrm{df}=3, p=0.001)$. As shown in Fig. 5, participants from the Supportive group were the most satisfied with life, with their results being significantly higher than those of the Ambivalent $(\mathrm{H}=38.209, \mathrm{SE}=11.534, p=$ $0.001)$ or Reluctant clusters $(\mathrm{H}=-34.101, \mathrm{SE}=11.620, p=$ $0.003)$.

\section{Discussion}

Siblings play a major role in human development. Brothers and sisters are the arena for training interpersonal competencies, they act as role models and serve as one of the basic
Fig. 4 The moderating effect of gender constellation in a sibling pair on the relationship between apathy and life satisfaction

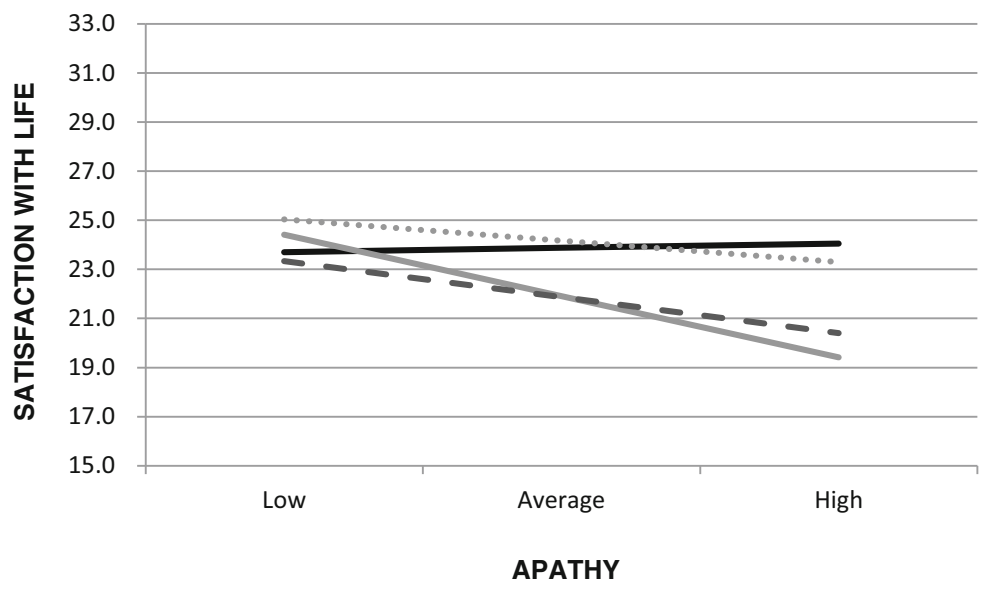

WOMEN-WOMEN

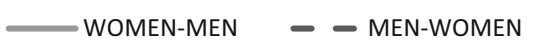

.... MEN-MEN 
Fig. 5 Rank distribution of life satisfaction across groups representing various types of sibling relation. Minimum and maximum ranks are presented

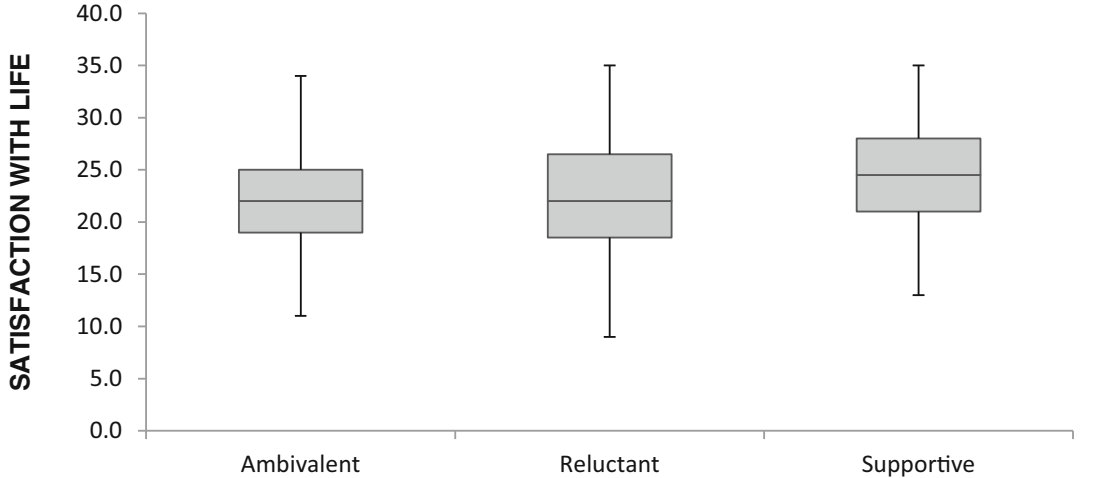

sources of emotional and instrumental support. Previous studies have found some links between life satisfaction and the quality of the sibling bond in adulthood (Hollifield and Conger 2015; Ponti and Smorti 2019; Walęcka-Matyja 2018). The current study analyses this relationship, highlights the significance of the sibling bond and certain demographic characteristics, mainly gender, in the process of shaping life satisfaction, and is the first to compare types of sibling relations in terms of overall satisfaction with life among young adults.

The results yielded partial support for two hypotheses about the role of sibling gender in determining the level of life satisfaction. Unexpectedly, unlike previous studies (Tay et al. 2014; Di Tella et al. 2003), no difference was revealed between men and women with regard to their individual cognitive judgments of global life satisfaction, what may be partially an effect of the uneven selection of participants in terms of gender. However, it is worth to notice that data regarding these variables are not consistent, e.g. Cabras and Mondo (2018) found higher level of life satisfaction among male participants, whereas other researchers found no gender difference (Batz-Barbarich et al. 2018; Bibi et al. 2015). Additionally, the level of overall satisfaction may be influenced by other variables, such as personality traits or sociodemographic features, i.e. age, education, marital status, employment or the place of residence (Joshanloo and Jovanović 2019). Hence, further studies are needed to acquire a greater understanding of the role of gender in shaping a global sense of well-being during mentioned period of life..

Consistent with the second hypothesis, based on previous findings, same-sex pairs, i.e. male participant and brother, female participant and sister, were characterized by higher levels of overall satisfaction with life than cross-sex siblings, i.e. male participant and sister or female participant and brother. These results are consistent with other studies. Same-sex siblings have more in common, including shared interests or activities, and face similar developmental problems and difficulties; they often imitate each in stressful and conflictual situations (Öz Soysal 2016; Stoneman et al. 1986). During earlier stages of development, such pairs of brothers and sisters are also more helpful and caring to each other, which can affect their future relationships (Tucker et al. 1997). Greater support and a sense of unity and closeness with a brother or a sister, resulting from the gender similarity, can contribute to a higher satisfaction with life. Furthermore, having a same-sex sibling has other consequences: it is also associated with an increased likelihood to form a family and achieve higher earnings in adulthood (Peter et al. 2018).

Regarding the effect of frequency of contact with siblings on the overall satisfaction, no difference was observed between participants communicating with a brother or a sister every day, and those communicating two to three times a week, once a week, once a month or rarer, what was not expected. On the contrary, significant results were obtained by Jensen et al. (2019), who reported greater general wellbeing among people remaining in more frequent with their sibling; however, the participants involved in the cited research were in their mid and late adulthood, with the mean age being nearly 60 years old. Similar findings, although referring to different family members and friends, were given by Pinquart and Sörensen (2000). It is therefore possible, that the influence of frequency of contact with a sibling may vary across the lifespan. During early adulthood, a period characterised by diversified support sources and a wide variety of individual tasks and challenges to complete, the intensity of contact seems not to be crucial; however, it appears to gain importance later in life due to developmental changes and common familial experiences, such as shared care for aging parents.

The study also provided an empirical analysis of the quality of the sibling relationship and global life satisfaction. Firstly, it was confirmed that a positive bond with a brother or a sister, characterised by high mutuality, intimacy and engagement, correlates with increased satisfaction with life. A negative relationship, i.e. demonstrating a high level of criticism, competition and apathy, was associated with its decreased level, whereas predominance was not at all connected to it. The results are in line with previous studies (Milevsky 2018a; Walęcka-Matyja 2018) indicating that life satisfaction is related to high closeness, acceptance and emotional support, as 
well as with low quarrelling and conflict. Additionally, sibling support and care may contribute to a lower level of mental problems (Milevsky 2005; Ponti and Smorti 2019). The existence of a high level of conflict in the relationship, however, triggers negative emotions such as anger, hate, envy or sadness; it also usually forces competitiveness and offensiveness, and requires the engagement of additional resources to resolve disagreements in an adaptive way. Functioning in such a demanding and intense relationship may foster coping problems or intrapersonal issues, such as decrease of life satisfaction, in the long term. It is also important that in contrast to childhood and adolescence, the overall level of conflict during the first years of adulthood decreases, and though, the relationship with global satisfaction may not be so easily distinguishable. Therefore, it is of great importance to include different age groups in subsequent studies.

As it was hypothesised analysis indicated that gender has two moderation effects on the relationship between sibling bond quality and general life satisfaction. In both cases, the relationship was statistically significant only for cross-sex sibling pairs. More specifically, a high level of mutuality predicted high satisfaction of life, while low apathy contributed to lower level of satisfaction. Few studies have examined the impact of the gender composition of sibling dyads on adult functioning, focusing mainly on their involvement in romantic relationship (Doughty et al. 2015; Hall and Willoughby 2018). Branje and colleagues (Branje et al. 2004) found gender constellation to have no effect on the relationship between perceived support and adolescent adjustment in a dyad. Thus, although this requires in-depth analysis it is possible that having an opposite-sex sibling may be a sensitizing factor towards aspects of the social relationships that are developed during early adulthood and that may influence global well-being at this life stage (Uecker 2012; Zhu et al. 2018).

New, compelling evidence has emerged underscoring the significance of the sibling relation type. The results supported the tested hypothesis. It was found that the Supportive type showed higher satisfaction with life than that Ambivalent and Reluctant types. Similar results, however related to well-being, were found by Walęcka-Matyja (2018) who reported higher well-being among Friendly Siblings than among Hostile or Occasional ones. Based on our current findings, and some previous studies, the Supportive or Friendly type appears to be characterised by the highest level of mutuality and closeness, and lowest level of conflict, dominance and rivalry with siblings. Partial evidence suggests also it is connected with low levels of social and romantic loneliness (Stewart et al. 2001; Szymańska 2019; Walęcka-Matyja 2018). High involvement in the relationship, together with a sense of belonging and unity, seem to fulfil the need for affiliation by an individual and may increase the level of contentment. Additionally, a previous analysis of childhood and youth experience implies that representatives of the Supportive or Friendly type were raised by emotionally warm, supportive parents, in families with balanced adaptability and cohesion (Szymańska 2019). These findings highlight the importance of developing a positive bond with the relatives, and indicate the broader context of life satisfaction formation, indicating also the fundamental role played by of family background.

\section{Practical Implications}

There are several clinical implications that emerge from these results. Firstly, as mentioned above, developing a close, emotional bond with siblings may be beneficial for general life satisfaction. Including brothers and sisters in the therapeutic process provides an additional source of support both during and after sessions while dealing with sibling or familyoriented issues. Applying a systematic approach, the relationship within the sibling subsystem is strictly connected to the whole family system and other subsystems. Due to the fact that the members interact and influence each other, the knowledge of how the sibling bond is formed may yield a deeper understanding of different family processes (Donley and Likins 2010). Practitioners should be also aware that strengthening reciprocity, building closeness and intimacy among siblings as well as bridging misunderstandings, and eliminating non-adaptive conflict and excessive competition, may contribute to increasing the level of life satisfaction and decreasing sense of loneliness (Milevsky 2018b; Walęcka-Matyja 2018). According to the presented research, it is especially effective in opposite-sex sibling dyads.

\section{Limitations}

Described findings provides an insight into the role of gender and the bond with a brother or a sister in the development of life satisfaction. However, it has a few limitations. Firstly, the purposive sampling method is a non-representative method that precludes to extrapolate findings on the general population. Even though the participant group was selected with the highest possible diversity in terms of education, place of residence, sibling age and gender, the sample was not equally distributed between sexes, being predominantly female. Nevertheless, such an approach may be useful for identifying any tendency within a study group that merits further analysis. Secondly, the analysis was limited to people with only one sibling: including siblings of more than two people may provide a possibility to investigate the role of additional variables such as birth order. Finally, the study is based on self-reported questionnaires completed by individuals with a brother or a sister, and as such it might be difficult to generalize the results. 


\section{Conclusion}

Early adulthood is a dynamic developmental period, requiring the young adult to implement multi-tasking and deal with difficulties in many areas of life. Moreover, it is also a time of increased susceptibility to various mental disorders. Therefore, to foster positive well-being, it appears crucial for the individual to be aware of and lay down various protective factors, features or relationships, such as that held with a brother or a sister. Additionally, knowing the clinical and developmental importance of sibling relationships, practitioners, therapists and psychologists are more willing to include siblings, directly or indirectly, in the therapeutic process (Namysłowska and Siewierska 2009; Sundaraja and Shah 2017).

Findings from the current study underscore an important point about the role of the sibling in the process of forming life satisfaction. Present findings confirm those of previous studies, in that they indicate higher life-satisfaction among same-sex sibling pairs, They enrich the existing literature by drawing attention to the importance of various aspects of the relationship with siblings, enhancing life satisfaction i.e. closeness, intimacy, positive emotionality, including happiness, shared experience and mutuality, low level of conflict, criticism, envy, competitiveness and disengagement in the relationship. The study is also the first to indicate that overall life satisfaction may be referenced to a particular type of relationship with a brother or a sister, thus serving as a foundation for further analyses. Finally, the study describes future research directions, and some practical and clinical implications stemming from its observations.

Funding Information The work has been funded by the University of Lodz as part of the Special-Purpose Subsidy for Scientific Research of the Dean of the Faculty of Educational Sciences, University of Lodz in 2016 - project entitled "Siblings in early adulthood - types of relationships and their conditions."

\section{Compliance with Ethical Standards}

\section{Conflict of Interest Author declares no conflict of interest.}

Ethical Approval All procedures performed in studies involving human participants were in accordance with the ethical standards of the institutional and/or national research committees and with the 1964 Helsinki declaration and its later amendments or comparable ethical standards.

Informed Consent Oral informed consent was obtained from all individual participants included in the study.

Open Access This article is licensed under a Creative Commons Attribution 4.0 International License, which permits use, sharing, adaptation, distribution and reproduction in any medium or format, as long as you give appropriate credit to the original author(s) and the source, provide a link to the Creative Commons licence, and indicate if changes were made. The images or other third party material in this article are included in the article's Creative Commons licence, unless indicated otherwise in a credit line to the material. If material is not included in the article's Creative Commons licence and your intended use is not permitted by statutory regulation or exceeds the permitted use, you will need to obtain permission directly from the copyright holder. To view a copy of this licence, visit http://creativecommons.org/licenses/by/4.0/.

\section{References}

Arthaud-Day, M. L., Rode, J. C., Mooney, C. H., \& Near, J. P. (2005). The subjective well-being construct: A test of its convergent, discriminant, and factorial validity. Social Indicators Research, 74, 445-476. https://doi.org/10.1007/s11205-004-8209-6.

Bacro, F., Coudronnière, C., Gaudonville, T., Galharret, J. M., Ferrière, S., Florin, A., \& Guimard, P. (2020). The French adaptation of the satisfaction with life scale (SWLS): Factorial structure, age, gender and time-related invariance in children and adolescents. European Journal of Developmental Psychology, 17(2), 307-316. https://doi. org/10.1080/17405629.2019.1680359.

Batz-Barbarich, C., Tay, L., Kuykendall, L., \& Cheung, H. K. (2018). A meta-analysis of gender differences in subjective well-being: Estimating effect sizes and associations with gender inequality. Psychological Science, 29(9), 1491-1503. https://doi.org/10.1177/ 0956797618774796.

Bibi, F., Chaudhry, A. G., \& Awan, E. A. (2015). Impact of gender, age and culture on life satisfaction. Science Inernational., 27(2), 1649 1652. Retrieved from https://www.academia.edu/.

Bogner, J. A., Corrigan, J. D., Mysiw, W. J., Clinchot, D., \& Fugate, L. (2001). A comparison of substance abuse and violence in the prediction of long-term rehabilitation outcomes after traumatic brain injury. Archives of Physical Medicine and Rehabilitation, 82(5), 571-577. https://doi.org/10.1053/apmr.2001.22340.

Branje, S. J. T., van Lieshout, C. F. M., van Aken, M. A. G., \& Haselager, G. J. T. (2004). Perceived support in sibling relationships and adolescent adjustment. Journal of Child Psychology and Psychiatry, and Allied Disciplines, 45(8), 1385-1396. https://doi.org/10.1111/j. 1469-7610.2004.00332.x.

Brody, G. H., \& Kim, S. (2003). Longitudinal direct and indirect pathways linking older sibling competence to the development of younger sibling competence. Developmental Psychology, 39(3), 618628. https://doi.org/10.1037/0012-1649.39.3.618.

Cabras, C., \& Mondo, M. (2018). Coping strategies, optimism, and life satisfaction among first-year university students in Italy: Gender and age differences. Higher Education, 75(4), 643-654. https://doi.org/ 10.1007/s10734-017-0161-x.

Caspi, J. (2011). Sibling aggression: Assessment and treatment. New York: Springer. Retrieved from https://books.google.pl/.

Cicirelli, V. G. (1995). Sibling relationships across the life span. New York: Plenum.

Cicognani, E., Pirini, C., Keyes, C., Joshanloo, M., Rostami, R., \& Nosratabadi, M. (2008). Social participation, sense of community and social well being: A study on American, Italian and Iranian University students. Social Indicators Research, 89(1), 97-112. https://doi.org/10.1007/s11205-007-9222-3.

Cyron, L., Schwerdt, G., \& Viarengo, M. (2017). The effect of opposite sex siblings on cognitive and noncognitive skills in early childhood. Applied Economics Letters, 24(19), 1369-1373. https://doi.org/10. 1080/13504851.2017.1279263.

Di Tella, R., Macculloch, R. J., \& Oswald, A. J. (2003). The macroeconomics of happiness. The Review of Economics and Statistics, 85(4), 809-827. https://doi.org/10.1162/003465303772815745.

Diener, E. (2006). Guidelines for national indicators of subjective wellbeing and ill-being. Applied Research in Quality of Life, 1(2), 151157. https://doi.org/10.1007/s11482-006-9007-x. 
Diener, E., \& Seligman, M. E. P. (2002). Very happy people. Psychological Science, 13(1), 81-84. https://doi.org/10.1111/1467-9280.00415.

Diener, E., Emmons, R. A., Larsen, R. J., \& Griffin, S. (1985). The satisfaction with life scale. Journal of Personality Assessment, 49(1), 71-74. https://doi.org/10.1207/s15327752jpa4901_13.

Diener, E., Suh, E. M., Lucas, R. E., \& Smith, H. L. (1999). Subjective well-being: Three decades of progress. Psychological Bulletin, 125(2), 276-302. https://doi.org/10.1037/0033-2909.125.2.276.

Doherty, N. A., \& Feeney, J. A. (2004). The composition of attachment networks throughout the adult years. Personal Relationships, 11(4), 469-488. https://doi.org/10.1111/j.1475-6811.2004.00093.x.

Donley, M. G., \& Likins, L. (2010). The multigenerational impact of sibling relationships. American Journal of Family Therapy, 38(5), 383-396. https://doi.org/10.1080/01926187.2010.513905.

Dorahy, M. J., Lewis, C. A., Schumaker, J. F., Akuamoah-Boateng, R., Duze, M. C., \& Sibiya, T. E. (2000). Depression and life satisfaction among Australian, Ghanaian, Nigerian, northern Irish, and Swazi University students. Journal of Social Behavior and Personality, 15(4), 569-580.

Doughty, S., Lam, C., Stanik, C., \& McHale, S. (2015). Links between sibling experiences and romantic competence from adolescence through young adulthood. Journal of Youth \& Adolescence, 44(11), 2054-2066. https://doi.org/10.1007/s10964-014-0177-9.

Fujita, F., \& Diener, E. (2005). Life satisfaction set point: Stability and change. Journal of Personality and Social Psychology, 88(1), 158164. https://doi.org/10.1037/0022-3514.88.1.158.

Gil, K. M., Carson, J. W., Porter, L. S., Scipio, C., Bediako, S. M., \& Orringer, E. (2004). Daily mood and stress predict pain, health care use, and work activity in African American adults with sickle-cell disease. Health Psychology, 23(3), 267-274. https://doi.org/10. 1037/0278-6133.23.3.267.

Goetting, A. (1986). The developmental tasks of siblingship over the life cycle. Journal of Marriage and the Family, 48(4), 703-714.

Gold, D. T. (1990). Late-life sibling relationships: Does race affect typological distribution?. The Gerontologist 30(6), 741-748. https://doi. org/10.1093/geront/30.6.741.

Goldscheider, F., \& Goldscheider, C. (1999). The changing transition to adulthood: Leaving and returning home. Thousand Oaks: SAGE Publications. https://doi.org/10.4135/9781452234014.

Gouveia, V. V., Milfont, T. L., da Fonseca, P. N., \& de Miranda Coelho, J. A. P. (2009). Life satisfaction in Brazil: Testing the psychometric properties of the satisfaction with life scale (SWLS) in five Brazilian samples. Social Indicators Research, 90(2), 267-277. https://doi. org/10.1007/s11205-008-9257-0.

Graham, C., Eggers, A., \& Sukhtankar, S. (2004). Does happiness pay? An exploration based on panel data from Russia. Journal of Economic Behavior and Organization, 55(3), 319-342. https://doi. org/10.1016/j.jebo.2003.09.002.

Haase, C. M., Heckhausen, J., \& Silbereisen, R. K. (2012). The interplay of occupational motivation and well-being during the transition from university to work. Developmental Psychology, 48(6), 1739-1751. https://doi.org/10.1037/a0026641.

Hall, S. S., \& Willoughby, B. J. (2018). Opposite-sex siblings and marital beliefs among emerging adults. Journal of Adult Development, 25(1), 61-67. https://doi.org/10.1007/s10804-017-9275-8.

Hamwey, M. K., Rolan, E. P., Jensen, A. C., \& Whiteman, S. D. (2019). "Absence makes the heart grow fonder": A qualitative examination of sibling relationships during emerging adulthood. Journal of Social and Personal Relationships, 36(8), 2487-2506. https://doi. org/10.1177/0265407518789514.

Havighurst, R. J. (1981). Developmental tasks and education. New York: Longman.

Haxhe, S., Cerezo, A., Bergfeld, J., \& Walloch, J. C. (2018). Siblings and the coming-out process: A comparative case study. Journal of Homosexuality, 65(4), 407-426. https://doi.org/10.1080/00918369. 2017.1321349.
Heller, D., Ilies, R., \& Watson, D. (2004). The role of person versus situation in life satisfaction: A critical examination. Psychological Bulletin, 130(4), 574-600. https://doi.org/10.1037/0033-2909.130.4.574.

Hindle, D., \& Sherwin-White, S. (2014). Sibling matters: A psychoanalytic, developmental, and systemic approach. London: Karnac. Retrieved from https://books.google.pl/.

Hinz, A., Conrad, I., Schroeter, M. L., Glaesmer, H., Brähler, E., Zenger, M., Kocalevent, R. D., \& Herzberg, P. Y. (2018). Psychometric properties of the satisfaction with life scale (SWLS), derived from a large German community sample. Quality of Life Research, 27(6), 1661-1670. https://doi.org/10.1007/s11136-018-1844-1.

Hollifield, C. R., \& Conger, K. J. (2015). The role of siblings and psychological needs in predicting life satisfaction during emerging adulthood. Emerging Adulthood, 3(3), 143-153. https://doi.org/10. $1177 / 2167696814561544$

Jenkins Tucker, C., Holt, M., \& Wiesen-Martin, D. (2013). Inter-parental conflict and sibling warmth during adolescence: Associations with female depression in emerging adulthood. Psychological Reports, 112(1), 243-251. https://doi.org/10.2466/21.10.PR0.112.1.243-251.

Jensen, A. C., Nielson, M. K., \& Yorgason, J. B. (2019). The longestlasting relationship: Patterns of contact and well-being among midto later-life siblings. The Journals of Gerontology: Series B. https:// doi.org/10.1093/geronb/gbz083.

Joshanloo, M., \& Jovanović, V. (2019). The relationship between gender and life satisfaction: Analysis across demographic groups and global regions. Archives of Women's Mental Health. https://doi.org/10. 1007/s00737-019-00998-w.

Juczyński, Z. (2009). Narzędzia pomiaru w promocji i psychologii zdrowia. Warszawa: Pracownia Testów Psychologicznych PTP.

Kolak, A. M., \& Volling, B. L. (2011). Sibling jealousy in early childhood: Longitudinal links to sibling relationship quality. Infant \& Child Development, 20(2), 213-226. https://doi.org/10.1002/icd.690.

Kosonen, M. (1996). Siblings as providers of support and care during middle childhood: Children's perceptions. Children \& Society, 10(4), 267-279.

Kothari, B. H., Sorenson, P., Bank, L., \& Snyder, J. (2014). Alcohol and substance use in adolescence and young adulthood: The role of siblings. Journal of Family Social Work, 17(4), 324-343. https:// doi.org/10.1080/10522158.2014.924457.

Kováts, D., Császár, N., Haller, J., Juhos, V., Sallay, V., Békés, J., Fabó, D., Rásonyi, G., Folyovich, A., \& Kurimay, T. (2017). Factors affecting quality of life in Hungarian adults with epilepsy: A comparison of four psychiatric instruments. Epilepsy and Behavior, 74, 4558. https://doi.org/10.1016/j.yebeh.2017.04.035.

López-Ortega, M., Torres-Castro, S., \& Rosas-Carrasco, O. (2016). Psychometric properties of the satisfaction with life scale (SWLS): Secondary analysis of the Mexican health and aging study. Health and Quality of Life Outcomes, 14(1), 170. https://oi.org/10.1186/ s12955-016-0573-9.

Lucas, R. E., Clark, A. E., Georgellis, Y., \& Diener, E. (2004). Unemployment alters the set point for life satisfaction. Psychological Science, 15(1), 8-13. https://doi.org/10.1111/j.09637214.2004.01501002.x.

Lucas, R. E., Diener, E., \& Suh, E. (1996). Discriminant validity of wellbeing measures. Journal of Personality and Social Psychology, 71(3), 616-628. https://doi.org/10.1037/0022-3514.71.3.616.

Lyubomirsky, S., King, L., \& Diener, E. (2005). The benefits of frequent positive affect: Does happiness lead to success? Psychological Bulletin, 131(6), 803-855. https://doi.org/10.1037/0033-2909.131.6.803.

Maslovska, K., Voitkāne, S., Miezīte, S., \& Raščevska, M. (2005). Reliability and validity of the adaptation of the satisfaction with life scale in Latvia. Baltic Journal of Psychology, 6(2), 25-36.

Merz, E.M., \& De Jong Gierveld, J. (2016). Childhood memories, family ties, sibling support and loneliness in ever-widowed older adults: quantitative and qualitative results. Ageing \& Society, 36(3), 534 561. https://doi.org/10.1017/S0144686X14001329. 
Milevsky, A. (2005). Compensatory patterns of sibling support in emerging adulthood: Variations in loneliness, self-esteem, depression and life satisfaction. Journal of Social and Personal Relationships, 22(6), 743-755. https://doi.org/10.1177/0265407505056447.

Milevsky, A. (2018a). Parental factors, psychological well-being, and sibling dynamics: A mediational model in emerging adulthood. Marriage and Family Review, 55(5), 476-492. https://doi.org/10. 1080/01494929.2018.1518822.

Milevsky, A. (2018b). Theoretical and clinical foundations of siblings in therapy: Use of parental context in adult sibling discord. American Journal of Family Therapy, 46(5), 437-453. https://doi.org/10. 1080/01926187.2018.1558423.

Milevsky, A., Smoot, K., Leh, M., \& Ruppe, A. (2005). Familial and contextual variables and the nature of sibling relationships in emerging adulthood. Marriage \& Family Review, 37(4), 123-141. https:// doi.org/10.1300/J002v37n04 07.

Mroczek, D. K., \& Spiro, A. (2005). Change in life satisfaction during adulthood: Findings from the veterans affairs normative aging study. Journal of Personality and Social Psychology, 88(1), 189-202. https://doi.org/10.1037/0022-3514.88.1.189.

Namysłowska, I., \& Siewierska, A. (2009). Znaczenie i rola rodzeństwa w terapii rodzin. Psychoterapia, 2(149), 45-56. Retrieved from http://www.psychoterapiaptp.pl/.

Öz Soysal, F. S. (2016). A study on sibling relationships, life satisfaction and loneliness level of adolescents. Journal of Education and Training Studies, 4(4), 58-67. https://doi.org/10.11114/jets.v4i4.1240.

Palmer, E. N. (2017). Using distance regulation for the study of sibling relationship quality, romantic relationships, and interpersonal and intrapersonal factors (doctoral dissertation). The Ohio State University, Columbus. Retrieved from https://etd.ohiolink.edu/

Paupério, T., Corte-Real, N., Dias, C., \& Fonseca, A. (2012). Sport, substance use and satisfaction with life: What relationship? European Journal of Sport Science, 12, 73-80. https://doi.org/10. 1080/17461391.2010.545836.

Pavot, W., \& Diener, E. (2008). The satisfaction with life scale and the emerging construct of life satisfaction. Journal of Positive Psychology, 3(2), 137-152. https://doi.org/10.1080/17439760701756946.

Peter, N., Lundborg, P., Mikkelsen, S., \& Webbink, D. (2018). The effect of a sibling's gender on earnings and family formation. Labour Economics, 54, 61-78. https://doi.org/10.1016/j.labeco.2018.06.006.

Pinquart, M., \& Sörensen, S. (2000). Influences of socioeconomic status, social network, and competence on subjective well-being in later life: A meta-analysis. Psychology and Aging, 15(2), 187-224. https://doi.org/10.1037/0882-7974.15.2.187.

Ponti, L., \& Smorti, M. (2019). The roles of parental attachment and sibling relationships on life satisfaction in emerging adults. Journal of Social \& Personal Relationships, 36(6), 1747-1763. https://doi.org/10.1177/0265407518771741.

Scholte, R. H. J., Engels, R. C. M. E., De Kemp, R. A. T., Harakeh, Z., \& Overbeek, G. (2007). Differential parental treatment, sibling relationships and delinquency in adolescence. Journal of Youth and Adolescence, 36(5), 661-671. https://doi.org/10.1007/s10964-0069155-1.

Seiffe-Krenke, I. (2006). Leaving home or still in the nest? Parent-child relationships and psychological health as predictors of different leaving home patterns. Developmental Psychology, 42, 864-876. https://doi.org/10.1037/0012-1649.42.5.864.

Seiffge-Krenke, I. (2013). "She's leaving home ..." Antecedents, consequences, and cultural patterns in the leaving home process. Emerging Adulthood, 1(2), 114-124. https://doi.org/10.1177/ 2167696813479783.

Sherman, A. M., Lansford, J. E., \& Volling, B. L. (2006). Sibling relationships and best friendships in young adulthood: Warmth, conflict, and well-being. Personal Relationships, 13(2), 151-156. https://doi. org/10.1111/j.1475-6811.2006.00110.x.
Shirkavand, L., Abbaszadeh, A., Borhani, F., \& Momenyan, S. (2018). Correlation between spiritual well-being with satisfaction with life and death anxiety among elderlies suffering from cancer. Electronic Journal of General Medicine, 15(3). https://doi.org/10.29333/ejgm/ 85501.

Simpson, P. L., Schumaker, J. F., Dorahy, M. J., \& Shrestha, S. N. (1996). Depression and life satisfaction in Nepal and Australia. Journal of Social Psychology, 136(6), 783-790. https://doi.org/10.1080/ 00224545.1996.9712255.

Stallman, H. M. (2010). Psychological distress in university students: A comparison with general population data. Australian Psychologist, 45(4), 249-257. https://doi.org/10.1080/00050067.2010.482109.

Stańczak, J., Stelmach, K., \& Urbanowicz, M. (2016). Małzeństwa oraz. dzietność w Polsce. Retrieved from https://stat.gov.pl/

Staw, B. M., Sutton, R. I., \& Pelled, L. H. (1994). Employee positive emotion and favorable outcomes at the workplace. Organization Science, 5(1), 51-71. https://doi.org/10.1287/orsc.5.1.51.

Stewart, R. B., Verbrugge, K. M., \& Beilfuss, M. C. (1998). Sibling relationships in early adulthood: A typology. Personal Relationships, 5(1), 59-74. https://doi.org/10.1111/j.1475-6811. 1998.tb00159.x.

Stewart, R. B., Kozak, A. L., Tingley, L. M., Goddard, J. M., Blake, E. M., \& Cassel, W. A. (2001). Adult sibling relationships: Validation of a typology. Personal Relationships, 8(3), 299-324. https://doi. org/10.1111/j.1475-6811.2001.tb00042.x.

Stoneman, Z., Brody, G. H., \& MacKinnon, C. E. (1986). Same-sex and cross-sex siblings: Activity choices, roles, behavior, and gender stereotypes. Sex Roles, 15(9-10), 495-511. https://doi.org/10.1007/ BF00288227.

Stubbe, J. H., Posthuma, D., Boomsma, D. I., \& De Geus, E. J. C. (2005). Heritability of life satisfaction in adults: A twin-family study. Psychological Medicine, 35(11), 1581-1588. https://doi.org/10. 1017/S0033291705005374.

Sundaraja, C. S., \& Shah, A. (2017). How to work with middle-aged siblings: Integration of narrative-behavioral approaches in family therapy. Journal of Family Psychotherapy, 28(1), 76-91. https:// doi.org/10.1080/08975353.2017.1279885.

Szafraniec, K. (2011). Młodzi 2011. Retrieved from https://nck.p1/

Szymańska, P. (2016). An analysis of sibling relationship in adulthood: STQNow, polish version. Archives of Psychiatry and Psychotherapy, 18(1), 55-64. https://doi.org/10.12740/APP/61610.

Szymańska, P. (2019). Uwarunkowania jakości relacji z rodzeństwem we wczesnej dorostości. Łódź: Wydawnictwo Uniwersytetu Łódzkiego. Retrieved from https://ibuk.pl.

Tay, L., Ng, V., Kuykendall, L., \& Diener, E. (2014). Demographic factors and worker well-being: An empirical review using representative data from the United States and across the world. Research in Occupational Stress and Well Being, 12, 235-283. https://doi.org/ 10.1108/S1479-355520140000012007.

Tucker, C. J., Barber, B. L., \& Eccles, J. S. (1997). Advice about life plans and personal problems in late adolescent sibling relationships. Journal of Youth and Adolescence, 26(1), 63-76. https://doi.org/ 10.1023/A:1024540228946.

Uecker, J. E. (2012). Marriage and mental health among young adults. Journal of Health and Social Behavior, 53(1), 67-83. https://doi. org/10.1177/0022146511419206.

Voorpostel, M., \& Blieszner, R. (2008). Intergenerational Solidarity and Support Between Adult Siblings. Journal of Marriage and Family, 1(70), 157-167. https://doi.org/10.1111/j.1741-3737.2007.00468.x.

Walęcka-Matyja, K. (2018). Relacje interpersonalne dorostych rodzeństw $w$ aspekcie funkcjonowania psychospołecznego. Łódź: Wydawnictwo Uniwersytetu Lódzkiego. Retrieved from https:// ibuk.pl.

White, L. (2001). Sibling relationships over the life course: A panel analysis. Journal of Marriage and Family, 63(2), 555-568. https://doi. org/10.1111/j.1741-3737.2001.00555.x. 
White, L. K., \& Riedmann, A. (1992). Ties among adult siblings. Social Forces, 71(1), 85-102. https://doi.org/10.2307/2579967.

Whiteman, S. D., McHale, S. M., \& Crouter, A. C. (2011). Family relationships from adolescence to early adulthood: Changes in the family system following firstborns' leaving home. Journal of Research on Adolescence, 21(2), 461-474. https://doi.org/10.1111/j.15327795.2010.00683.x.

Xiong, C. Q., \& Xu, Y. L. (2009). Reliability and validity of the satisfaction with life scale for Chinese people. China Journal of Health Psychology, 17(8), 948-949.
Zhu, X., Wang, K., Chen, L., Cao, A., Chen, Q., Li, J., \& Qiu, J. (2018). Together means more happiness: Relationship status moderates the association between brain structure and life satisfaction. Neuroscience, 384, 406-416. https://doi.org/10.1016/j. neuroscience.2018.05.018.

Publisher's Note Springer Nature remains neutral with regard to jurisdictional claims in published maps and institutional affiliations. 